\title{
Subacute Therapeutic Dosing of Artemether-Lumefantrine and Artesunate-Amodiaquine Combination Preserves Plasma Cholesterol, Renal Antioxidant Status, and Organ Weights in Rats
}

\author{
Chiagoziem A. Otuechere, ${ }^{1}$ Gloria Edewor, ${ }^{1}$ Oluwafemi Ezekiel Kale, ${ }^{2}$ and Martins Ekor ${ }^{1}$ \\ ${ }^{1}$ Department of Chemical Sciences, Redeemer's University, PMB 2011, Mowe, Ogun, Nigeria \\ ${ }^{2}$ Department of Pharmacology, Olabisi Onabanjo University, PMB 2002, Ago-Iwoye, Ogun, Nigeria \\ Correspondence should be addressed to Chiagoziem A. Otuechere, goziemo12@yahoo.com
}

Received 26 December 2011; Accepted 30 May 2012

Academic Editor: Neena Valecha

Copyright (C) 2012 Chiagoziem A. Otuechere et al. This is an open access article distributed under the Creative Commons Attribution License, which permits unrestricted use, distribution, and reproduction in any medium, provided the original work is properly cited.

\begin{abstract}
Recent instances of breakdowns of malaria control programs and the constant emergence of drug-resistant parasites to monotherapies have shored up the use of artemisinin-based combination therapy (ACT) as the malaria therapy of choice. We evaluated a subacute therapeutic dosing of artemether-lumefantrine and artesunate-amodiaquine on plasma cholesterol, renal antioxidants, and organ weights in rats. Sixteen albino rats were grouped into three. Group A $(n=5)$ served as the control. Groups $\mathrm{B}(n=6)$ and $\mathrm{C}(n=5)$ were administered, twice daily, oral therapeutic doses of artemether-lumefantrine $(1.14 / 6.86 \mathrm{mg} / \mathrm{kg} / \mathrm{d})$ and artesunate-amodiaquine $(2.86 / 8.58 \mathrm{mg} / \mathrm{kg} / \mathrm{d})$, respectively, for seven days. From our results, ACTs did not significantly $(P>0.05)$ alter catalase, superoxide dismutase, glutathione S-transferase, myeloperoxidase, and total glutathione levels when compared with the control. Plasma total cholesterol levels also decreased insignificantly $(P>0.05)$. Organ-system weights were not significantly $(P>0.05)$ different from control rats. Artesunate-amodiaquine, but not artemether-lumefantrine, significantly increased $(P<0.05)$ lactate dehydrogenase activity and also afforded a $27.2 \%$ decrease in heart weight when compared with control. Also, both ACTs increased $(P<0.05)$ lipid peroxidation. Overall, artesunate-amodiaquine and artemether-lumefantrine may preserve renal antioxidants and organ weights in vivo. However, caution is required above therapeutic indications or in chronic doses as this may predispose to renal oxidative stress.
\end{abstract}

\section{Introduction}

Malarial infection is an important tropical mosquito-borne infectious disease that kills approximately three million per year. Statistics show that close to five billion episodes of clinical illness possibly meriting antimalarial therapy occur throughout the world, with Africa having more than $90 \%$ of this burden $[1,2]$. Over the years, different categories of plasmodia specie (Plasmodium falciparum, ovale, vivax, and malaria) evolved with several newly observed mechanisms of resistance. The emergence and spread across sub-Saharan Africa of Plasmodium falciparum resistance among others to the inexpensive antimalarials chloroquine and sulfadoxinepyrimethamine have worsened the pandemic and hampered the socioeconomic development of affected countries [3].
Following increased resistance of malaria parasites to conventional drugs in the malarial regions of the world, the WHO has been promoting artemisinin-based combination therapy (ACT) for treating uncomplicated malaria $[1,4]$. Artemisinin and its related compounds enhance efficacy of ACT and have the potential of lowering the rate at which resistance emerges and spreads. The ACTs are particularly known to be most effective because of their high killing rates, and they have become the mainstay chemotherapeutic agents for malaria [5]. Under low transmission intensity, ACTs have an additional public health benefit of reducing the overall malaria transmission and studies have recently demonstrated this synergistic benefit under high transmission [6]. ACTs offer the advantages of countering the increasing challenge of antimalarial drug resistance as well 
as an improved and highly effective treatment $[7,8]$. In fact, several countries in Africa have adopted the use of ACT combination methods as far back as 2000, and it has provided an effective management central to the reduction of malaria mortality and morbidity worldwide. However, unfortunately, only a minority of those affected by malaria have access to prompt effective treatment in most parts of Africa $[9,10]$.

There has been increasing and expanding knowledge of safety profiles of ACT with focus on animals as well as human data including pharmacovigilance activities in the implementation process of therapy changes in order to evaluate fully its effect on the populace [11].

In areas where malaria is endemic, patients often prefer one ACT to another. Up to now, evidence abounds that despite the limited malaria parasite resistance to ACT therapy, their in vivo as well as in vitro assessment remains an ongoing process. Whether as a single monotherapy or in combination, the fate of ACTs in populations required a continuous evaluation and several authors have documented the reports of their studies [12-15]. Interestingly, of these studies, renal antioxidants activities of ACTs as well as lipid peroxidation however are rarely discussed. Therefore, in order to aid diagnosis and enhance therapeutic options, in this present study, we evaluated a subacute therapeutic administration of artemether-lumefantrine and artesunateamodiaquine combination on plasma total cholesterol, renal antioxidants, and organ weights in an experimental rat model.

\section{Materials and Methods}

2.1. Drug and Chemicals. Artemether + lumefantrine (lonart) and Artesunate + amodiaquine (camosunate) Bliss Gvs Pharma Ltd., India, and Adams Pharmaceutical Co. Ltd. (China). Thiobarbituric acid (TBA) and $5^{\prime}, 5^{\prime}$-dithiobis-2nitrobenzoate (Ellman's reagent) were purchased from Sigma Chemical Company (USA). Reduced glutathione (GSH), metaphosphoric acid, and trichloroacetic acid (TCA) were purchased from J. I. Baker (USA). Total cholesterol (TC) and lactate dehydrogenase assay kits was obtained from Randox Laboratory (Crumlin, UK). All other chemicals and reagents used were of analytical grade.

2.2. Animals. Sixteen (16) white albino rats weighing between 120 and $180 \mathrm{~g}$ of both sexes were obtained from Covenant Farm Academy, Iwo Road, Ibadan, Oyo-State, Nigeria, and were housed within the experimental animal handling facility of the College of Natural Sciences, Redeemers University, Nigeria, at ambient temperature and humidity with a $12 \mathrm{~h}$ light $/ 12 \mathrm{~h}$ dark schedule. They were placed on rat pellets diet and water ad libitum during the period of acclimatization and throughout the period of the experiment. Study was in accordance with established guidelines for care and use of the laboratory animals in biomedical research. The experiment was approved by the Animal Ethics Committee of Redeemer's University.

\section{Experimental Design}

Sixteen (16) white albino rats were divided into three groups. Treatment was provided in all groups two times daily at therapeutic doses calculated based on the assumed average weight of $70 \mathrm{~kg}$ for a physiological man. Group A $(n=5)$ was given no treatment and served as negative control in this study. Group B $(n=6)$ was administered therapeutic dose of artemeter-lumefantrine (lonart), 1.14/6.86 mg/kg/d). Group C $(n=5)$ was administered therapeutic dose of artesunate-amodiaquine (camosunate), $2.86 / 8.58 \mathrm{mg} / \mathrm{kg} / \mathrm{d}$ ). The treatments (using intragastric feeding needle) were continued for seven days.

3.1. Necropsy. All animals were sacrificed by cervical dislocation, absence of general anesthesia, 24 hours following the last treatment and blood collected by cardiac puncture into lithium heparin bottles. Plasma was separated after centrifugation at 4,500 $\mathrm{g}$ at room temperature for 25 minutes. The kidney was carefully excised, cleared of adhering tissues, and weighed. The weight was recorded in grams and expressed as $\mathrm{g} / \mathrm{kg}$ body weight. The excised kidney was weighed and homogenized in four volumes of $100 \mathrm{mM}$ phosphate buffer $(\mathrm{pH}$ 7.4). All the proceedings were carried out at a temperature not exceeding $4^{\circ} \mathrm{C}$. The plasma and kidney homogenate obtained from each animal were then analyzed to assess kidney antioxidants levels and other biochemical parameters.

3.2. Biochemical Analysis. GSH level was estimated at $412 \mathrm{~nm}$ following the method of Beutler et al. [16, 17]. Lipid peroxidation was estimated spectrophotometrically by the thiobarbituric acid reactive substance (TBARS) method as described by Varshney and Kale [18] and expressed in terms of malondialdehyde (MDA) formed per mg protein. GST activity determined according to Habig et al. [19]. Plasma total cholesterol (TC) concentration was estimated following the principle described by Trinder [20]. Lactate dehydrogenase activity was estimated in plasma according to the procedures using Randox commercial kit. Catalase activity was determined according to the methods of Sinha [21]. Superoxide dismutase (SOD) activity was determined by the method of Misra and Fridovich [22]. Myeloperoxidase (MPO) activity, an indicator of polymorphonuclear leukocyte accumulation, was determined according to the method of Eiserich et al. [23].

\section{Statistics}

Differences between groups were determined by one-way analysis of variance (ANOVA), and post hoc testing was performed for intergroup comparisons using the least significant difference (LSD) [24]. Data presented are mean \pm standard error of mean (SEM) and were analyzed using Statistical Package for Social Sciences (SPSS) software for windows. $P<0.05$ was considered significant. 


\section{Results}

5.1. Effect of $A+L$ and $A+A$ on Plasma Biomarkers. Figure 1 summarizes the effects of artemether-lumefantrine and artesunate-amodiaquine combination on plasma total cholesterol and lactate dehydrogenase levels in rats. From the results, total cholesterol levels decreased in plasma of all animals given therapeutic doses of artemether-lumefantrine $(1.14 / 6.86 \mathrm{mg} / \mathrm{kg} / \mathrm{d})$ and artesunate-amodiaquine $(2.86 / 8.58$ $\mathrm{mg} / \mathrm{kg} / \mathrm{d}$ ), although statistics showed this not to be statistically significant $(P>0.05)$ when compared with control. Furthermore, we assessed lactate dehydrogenase (LDH) as a biomarker of renal function. Results show that artemetherlumefantrine $(1.14 / 6.86 \mathrm{mg} / \mathrm{kg} / \mathrm{d})$ administered at a therapeutic dose increased LDH insignificantly $(P>0.05)$ while equal molar of artesunate-amodiaquine $(2.86 / 8.58 \mathrm{mg} / \mathrm{kg} / \mathrm{d})$ therapeutically increased LDH level significantly $(P<0.05)$ in this study (Figure 1).

5.2. Effect of $A+L$ and $A+A$ on Renal Antioxidant Status. From the result obtained, catalase slightly increased insig-nificantly $(P>0.05)$ in both artemeter-lumefantrine $(1.14 / 6.86 \mathrm{mg} / \mathrm{kg} / \mathrm{d})$ and artesunate-amodiaquine $(2.86 / 8.58$ $\mathrm{mg} / \mathrm{kg} / \mathrm{d}$ ) when compared with the control group that was given no treatment. Also, superoxide dismutase increased insignificantly as well, although this was more pronounced in artesunate-amodiaquine than artemeter-lumefantrine when compared with control. Glutathione S-transferase level increased insignificantly $(P>0.05)$ in artesunateamodiaquine- $(2.86 / 8.58 \mathrm{mg} / \mathrm{kg} / \mathrm{d})$ treated rats when compared with control. However, the effect of artemetherlumefantrine $(1.14 / 6.86 \mathrm{mg} / \mathrm{kg} / \mathrm{d})$ on the GST activity was similar to those of control animals. The level of total glutathione was not to any extent altered in animals treated with therapeutic dose of artemether-lumefantrine $(1.14 / 6.86 \mathrm{mg} / \mathrm{kg} / \mathrm{d})$ when compared with control whereas artesunate-amodiaquine $(2.86 / 8.58 \mathrm{mg} / \mathrm{kg} / \mathrm{d})$ increased GSH four times the control group, although this was not statistically significant (Table 1).

5.3. Effect of $A+L$ and $A+A$ on Lipid Peroxidation and Myeloperoxidase Levels. Lipid peroxidation was measured as malondialdehyde in this study. Artemether-lumefantrine $(1.14 / 6.86 \mathrm{mg} / \mathrm{kg} / \mathrm{d})$ and artesunate-amodiaquine $(2.86 / 8.58$ $\mathrm{mg} / \mathrm{kg} / \mathrm{d}$ ) both at therapeutic doses significantly increased $(P<0.05)$ MDA level by $76.5 \%$ and $82.4 \%$ when compared with control (Table 1).

Myeloperoxidase activity was also evaluated in rat kidney following artemether-lumefantrine $(1.14 / 6.86 \mathrm{mg} / \mathrm{kg} / \mathrm{d})$ and artesunate-amodiaquine $(2.86 / 8.58 \mathrm{mg} / \mathrm{kg} / \mathrm{d})$ administration but was not significantly increased $(P>0.05)$ when compared with that of control animals (Figure 1).

5.4. Effect of $A+L$ and $A+A$ on Rat Organ Weights. Artemether-lumefantrine $(1.14 / 6.86 \mathrm{mg} / \mathrm{kg} / \mathrm{d})$ and artesunate-amodiaquine $(2.86 / 8.58 \mathrm{mg} / \mathrm{kg} / \mathrm{d})$ given at therapeutic doses did not alter kidney, liver, and brain weights, respectively, in these animals when compared with control.

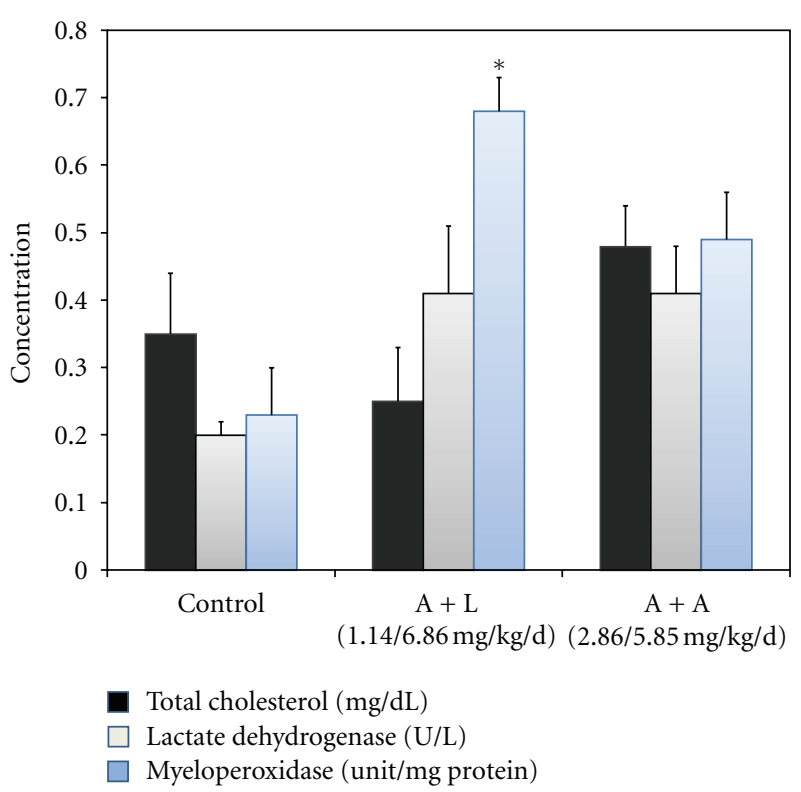

Figure 1: Effect of artemether-lumefantrine and artesunateamodiaquine combinations on total cholesterol, lactate dehydrogenase, and myeloperoxidase in rats. Results are expressed as mean \pm SEM. ${ }^{*} P<0.05$ when compared with control. A $+\mathrm{L}$ : artemether + lumefantrine; $\mathrm{A}+\mathrm{A}$ : artesunate + amodiaquine.

However, artemether-lumefantrine $(1.14 / 6.86 \mathrm{mg} / \mathrm{kg} / \mathrm{d})$ but not artesunate-amodiaquine $(2.86 / 8.58 \mathrm{mg} / \mathrm{kg} / \mathrm{d})$ increased lung weight insignificantly when compared with control. Also, artesunate-amodiaquine $(2.86 / 8.58 \mathrm{mg} / \mathrm{kg} / \mathrm{d})$ significantly decreased $(P<0.05)$ heart weight by $27.2 \%$ whereas artemether-lumefantrine $(1.14 / 6.86 \mathrm{mg} / \mathrm{kg} / \mathrm{d})$ did not alter the weight of the heart when compared with the control in this experiment (Table 2).

\section{Discussion}

Because of the high resistance and toxicity profiles of the older antimalarial agents, virtually all malaria-endemic countries have almost switched antimalarial drug policy to artemisinin combination therapies (ACTs). The change of first-line treatment of uncomplicated malaria to artemisinin combination therapy (ACT) is widespread in Africa [11], and there is need for continuous monitoring to keep track of any negative effects on various organs and biochemical parameters. In our present study, we evaluated a subacute therapeutic administration of two different ACTs, artemetherlumefantrine and artesunate-amodiaquine combination on total cholesterol, renal antioxidants, and organ weights in an experimental rat model. Artesunate-amodiaquine combination alone showed a higher but insignificant free scavenging activities in superoxide dismutase $(P=0.07)$, catalase $(P>0.05)$, and total glutathione $(P>0.05)$ levels when compared with the artemether-lumefantrine-treated group. Similarly, plasma total cholesterol remained unaltered insignificantly $(P>0.05)$ in these animals when compared with control group. Our study supports the earlier suggestion 
TABLE 1: Effects of artemether-lumefantrine and artesunate-amodiaquine combination on renal antioxidants and lipid peroxidation levels in rats.

\begin{tabular}{lccccc}
\hline Treatments & CAT $^{\mathrm{a}}$ & SOD $^{\mathrm{b}}$ & GST $^{\mathrm{c}}$ & GSH $^{\mathrm{c}}$ & MDA $^{\mathrm{d}}$ \\
\hline Control & $0.153 \pm 0.01$ & $0.24 \pm 0.06$ & $0.64 \pm 0.03$ & $0.022 \pm 0.001$ & $0.017 \pm 0.002$ \\
$\mathrm{~A}+\mathrm{L}$ & $0.160 \pm 0.01$ & $0.50 \pm 0.21$ & $0.63 \pm 0.03$ & $0.021 \pm 0.001$ & $0.030 \pm 0.002^{*}$ \\
$(1.14 / 6.86 \mathrm{mg} / \mathrm{kg} / \mathrm{d})$ & $(-4.6)^{\mathrm{a}}$ & $(-108.3)^{\mathrm{a}}$ & $(1.6)^{\mathrm{a}}$ & $(4.5)^{\mathrm{a}}$ & $(-76.5)^{\mathrm{a}}$ \\
$\mathrm{A}+\mathrm{A}$ & $0.170 \pm 0.02$ & $0.95 \pm 0.04$ & $0.49 \pm 0.07$ & $0.091 \pm 0.065$ & $0.031 \pm 0.006^{*}$ \\
$(2.86 / 8.58 \mathrm{mg} / \mathrm{kg} / \mathrm{d})$ & $(-11.1)^{\mathrm{a}}$ & $(-295.8)^{\mathrm{a}}$ & $(23.4)^{\mathrm{a}}$ & $(-313.6)^{\mathrm{a}}$ & $(-82.4)^{\mathrm{a}}$ \\
\hline
\end{tabular}

Results expressed as mean \pm SEM. Values in parenthesis represent $\%$ change; $(-)$ : increase; $(+)$ : decrease, (a) $\%$ change relative to control group. ${ }^{*} P<0.05$ when compared with control. ${ }^{a}$ Expressed as units in $\mu \mathrm{mol} / \mathrm{mL} / \mathrm{mg}$ protein; ${ }^{\mathrm{b}}$ activity expressed as units $/ \mathrm{mg}$ protein; ${ }^{\mathrm{c}}$ activity expressed as nmoles $/ \mathrm{mg}$ protein; ${ }^{d}$ concentration expressed as nmoles/mg protein; A + L: artemether + lumefantrine; A + A: artesunate + amodiaquine; CAT: catalase, SOD: superoxide dismutase, GST: glutathione s-transferase; GSH: total glutathione, MDA: malondialdehyde.

TABLE 2: Effects of artemether-lumefantrine and artesunate-amodiaquine combination on organ systems relative to their body weights in rats.

\begin{tabular}{|c|c|c|c|c|c|}
\hline Treaments & $\mathrm{LW}^{\mathrm{a}}$ & $\mathrm{KDW}^{\mathrm{a}}$ & $\mathrm{LGW}^{\mathrm{a}}$ & HTW $^{\mathrm{a}}$ & $\mathrm{BRW}^{\mathrm{a}}$ \\
\hline Control & $26.94 \pm 2.78$ & $6.10 \pm 0.64$ & $7.99 \pm 1.61$ & $3.89 \pm 0.45$ & $3.45 \pm 0.51$ \\
\hline $\mathrm{A}+\mathrm{L}$ & $25.41 \pm 1.75$ & $5.36 \pm 0.29$ & $9.39 \pm 1.95$ & $3.53 \pm 0.52$ & $4.47 \pm 0.09$ \\
\hline$(1.14 / 6.86 \mathrm{mg} / \mathrm{kg} / \mathrm{d})$ & $(6.68)^{\mathrm{a}}$ & $(12.1)^{\mathrm{a}}$ & $(-17.5)^{\mathrm{a}}$ & $(9.3)^{\mathrm{a}}$ & $(-26.2)^{\mathrm{a}}$ \\
\hline$A+A$ & $24.30 \pm 0.66$ & $4.70 \pm 0.64$ & $7.02 \pm 1.06$ & $2.83 \pm 0.15^{*}$ & $5.64 \pm 0.56$ \\
\hline$(2.86 / 8.58 \mathrm{mg} / \mathrm{kg} / \mathrm{d})$ & $(9.8)^{\mathrm{a}}$ & $(23.0)^{\mathrm{a}}$ & $(12.1)^{\mathrm{a}}$ & $(27.2)^{\mathrm{a}}$ & $(-63.5)^{\mathrm{a}}$ \\
\hline
\end{tabular}

Results expressed as mean \pm SEM. Values in parenthesis represent $\%$ change; $(-)$ : increase; $(+)$ : decrease, (a) $\%$ change relative to control group. ${ }^{*} P<0.05$ when compared with control. ${ }^{~}$ Expressed units as g/kg body weight. A + L: artemether + lumefantrine; A + A: artesunate + amodiaquine; LW: liver weight; KDW: kidney weight; LGW: lung weight; HTW: heart weight; BRW; brain weight.

of Obianime and Aprioku [15] on the anticholesteremic action of ACTs.

MDA is a good indication of the degree of lipid peroxidation and tissue damage. The MDA levels in treated rat significantly increased when compared with the control group. There was a significant increase $(P<0.05)$ in malondialdehyde levels in both artemether-lumefantrine$(1.14 / 6.86 \mathrm{mg} / \mathrm{kg} / \mathrm{d})$ and artesunate-amodiaquine- $(2.86 / 8.58$ $\mathrm{mg} / \mathrm{kg} / \mathrm{d}$ ) treated rats when compared with that of control rats. This agrees with another study that reported an increase in testis malondialdehyde levels in rats administered $10 \mathrm{mg} / 60 \mathrm{mg} / \mathrm{kg}$ b.w of artemether-lumefantrine for 3 days, indicating a clear manifestation of excessive formation of free radicals and activation of lipid peroxidation systems [25]. In addition, artesunate-amodiaquine but not artemeterlumefantrine increased significantly $(P<0.05)$ lactate dehydrogenase level when compared with control. While we observed for the first time that artesunate-amodiaquine may play a role in lactate metabolism, some earlier studies have as well demonstrated cardiac modulatory properties of artesunate, and atroquinine-like compounds [14, 26, 27]. Nosten and White [28] had also reported that artemisinin and its derivatives on their own may have relatively low toxicological effects with the suggestion that any toxicity observed in artemisinin combination treatments may be due to the partner agent(s). However, further studies may be required to unfold the mechanisms by which ACT modulates lactate metabolism as well as the cardiac functions. As seen in our study, the effectiveness of artesunate-amodiaquine combination or other ACTs therapy is not without side effects. This has in part been attributed to the transient drug-induced fever of artesunate and its transient first-degree heart block reported as a rare event [29]. It is therefore necessary that studies involving ACTs be given an urgent attention and caution be exercised in patients with history of cardiac disorders. Analysis of organ weight in toxicology studies is an important endpoint for identification of potentially harmful effects of chemicals. In this study, kidney, liver, lung, and brain weights in relation to body weight were not significantly $(P>0.05)$ altered except for artesunate-amodiaquine which decreased heart weight by $27.2 \%$ when compared with control. This correlates with a recent study which reported that dihydroartemisinin-piperaquine, artesunate-amodiaquine, artesunate-sulphadoxine/pyrimethamine, artemether plus lumefantrine, and artesunate mefloquine combinations elicited no significant treatment-related histopathological changes in the liver and kidney in experimental mice [30]. Based on these observations, the authors concluded that the ACTs as administered presently for the treatment of malaria are relatively safe. In conclusion, antimalarial activities of artesunate-amodiaquine and artemether-lumefantrine may preserve renal antioxidants as well as organ system effects in addition to their lowering of total cholesterol levels, though not statistically significant as observed in our experiment. However, as observed in this study, caution must be taken when administering doses above the therapeutic indications or chronic administration as these may predispose to oxidative damage and/or precipitate cardiac toxicity. 


\section{References}

[1] A. Ogbonna and C. J. Uneke, "Artemisinin-based combination therapy for uncomplicated malaria in sub-Saharan Africa: the efficacy, safety, resistance and policy implementation since Abuja 2000," Transactions of the Royal Society of Tropical Medicine and Hygiene, vol. 102, no. 7, pp. 621-627, 2008.

[2] D. O. Simba, M. Warsame, D. Kakoko et al., "Who gets prompt access to artemisinin-based combination therapy? A prospective community-based study in children from rural kilosa, Tanzania," PLoS ONE, vol. 5, no. 8, Article ID e12104, 2010.

[3] L. Matowe and O. Adeyi, "The quest for universal access to effective malaria treatment: how can the AMFm contribute?" Malaria Journal, vol. 9, no. 1, article 274, 2010.

[4] J. T. Lin, J. J. Juliano, and C. Wongsrichanalai, "Drug-resistant Malaria: the era of ACT," Current Infectious Disease Reports, vol. 12, no. 3, pp. 165-173, 2010.

[5] R. K. Haynes, "Artemisinin and derivatives: the future for malaria treatment?" Current Opinion in Infectious Diseases, vol. 14, no. 6, pp. 719-726, 2001.

[6] A. A. Amin, D. Zurovac, B. B. Kangwana et al., "The challenges of changing national malaria drug policy to artemisinin-based combinations in Kenya," Malaria Journal, vol. 6, article 72, 2007.

[7] J. H. Amuasi, G. Diap, S. Blay-Nguah et al., "Access to artesunate-amodiaquine, quinine and other anti-malarials: policy and markets in Burundi," Malaria Journal, vol. 10, article 34, 2011.

[8] J. Chuma, T. Abuya, D. Memusi et al., "Reviewing the literature on access to prompt and effective malaria treatment in Kenya: implications for meeting the Abuja targets," Malaria Journal, vol. 8, no. 1, article 243, 2009.

[9] J. Chuma, V. Okungu, and C. Molyneux, "Barriers to prompt and effective malaria treatment among the poorest population in Kenya," Malaria Journal, vol. 9, no. 1, article 144, 2010.

[10] T. K. Mutabingwa, "Artemisinin based combination therapy (ACTs): best hope for malaria treatment but inaccessible to the needy!," Acta Tropica, vol. 95, no. 3, pp. 305-315, 2005.

[11] A. N. O. Dodoo, C. Fogg, A. Asiimwe et al., "Pattern of drug utilization for treatment of uncomplicated malaria in urban Ghana following national treatment policy change to artemisinin-combination therapy," Malaria Journal, vol. 8, no. 1, article 2, 2009.

[12] F. Nosten, M. Van Vugt, R. Price et al., "Effects of artesunatemefloquine combination on incidence of Plasmodium falciparum malaria and mefloquine resistance in western Thailand: a prospective study," The Lancet, vol. 356, no. 9226, pp. 297 $302,2000$.

[13] A. A. Ngokere, T. C. Ngokere, and A. P. Ikwudinma, "Acute study of histomorphological and biochemical changes caused by artesunate in visceral organs of the rabbit," Journal of Experimental and Clinical Anatomy, vol. 3, no. 2, pp. 11-16, 2004.

[14] M. Traebert and B. Dumotier, "Antimalarial drugs: QT prolongation and cardiac arrhythmias," Expert Opinion on Drug Safety, vol. 4, no. 3, pp. 421-431, 2005.

[15] A. W. Obianime and J. S. Aprioku, "Comparative study of artesunate, ACTs and their combinants on the biochemical parameters of male guinea-pigs," African Journal of Biotechnology, vol. 8, no. 19, pp. 5059-5065, 2009.

[16] E. Beutler, O. Duron, and B. M. Kelly, "Improved method forthe determination of blood glutathione," The Journal of Laboratory and Clinical Medicine, vol. 61, pp. 882-888, 1963.
[17] E. Beutler, O. Duron, and B. M. Kelly, "Improved method for the determination of blood," Clinical Biochemistry, vol. 6, pp. 24-27, 1963.

[18] R. Varshney and R. K. Kale, "Effects of calmodulin antagonists on radiation-induced lipid peroxidation in microsomes," International Journal of Radiation Biology, vol. 58, no. 5, pp. 733-743, 1990.

[19] W. H. Habig, M. J. Pabst, and W. B. Jakoby, "Glutathione $S$ transferases. The first enzymatic step in mercapturic acid formation," The Journal of Biological Chemistry, vol. 249, no. 22-25, pp. 7130-7139, 1974.

[20] P. Trinder, "Quantitative determination of triglyceride using GPO-PAP method," Annals of Clinical Biochemistry, vol. 6, pp. 24-27, 1969.

[21] A. K. Sinha, "Colorimetric assay of catalase," Analytical Biochemistry, vol. 47, no. 2, pp. 389-394, 1972.

[22] H. P. Misra and I. Fridovich, "The role of superoxide anion in the autoxidation of epinephrine and a simple assay for superoxide dismutase," The Journal of Biological Chemistry, vol. 247, no. 10, pp. 3170-3175, 1972.

[23] J. P. Eiserich, M. Hristova, C. E. Cross et al., "Formation of nitric oxide-derived inflammatory oxidants by myeloperoxidase in neutrophils," Nature, vol. 391, no. 6665, pp. 393-397, 1998.

[24] G. Levine, A Guide To SPSS For Analysis of Variance, Lawrence Erlbaum, Hillsdale, NJ, USA, 1991.

[25] A. S. Tijani, V. O. Ukwenya, G. A. Sodunke, and J. B. Fakunle, "Acute administration of co-artesiane induces oxidative stress in the testes of adult male Wistar rats," Bioscience Research Communications, vol. 22, no. 5, BRC, 2010132/22506, 2010.

[26] E. O. Ajani, P. D. Shallie, B. O. Adegbesan, B. A. Salau, and M. Adesanya, "Protective effect of Garcinia Kola (Kolaviron) extract on predisposition of rats to cardiovascular diseases following separate administration of amodiaquine and artesunate," African Journal of Traditional, Complementary and Alternative Medicines, vol. 5, no. 2, pp. 180-186, 2008.

[27] J. O. Adebayo, A. Igunnu, R. O. Arise, and S. O. Malomo, "Effects of co-administration of artesunate and amodiaquine on some cardiovascular disease indices in rats," Food and Chemical Toxicology, vol. 49, no. 1, pp. 45-48, 2011.

[28] F. Nosten and N. J. White, "Artemisinin-based combination treatment of Falciparum malaria," The American Journal of Tropical Medicine and Hygiene, vol. 77, no. 6, supplement, pp. 181-192, 2007.

[29] World Health Organisation, The Role of Artemisinin and Its Derivatives in the Current Treatment of Malaria, 1067, World Health Organisation, Geneva, Switzerland, 1994.

[30] U. Georgewill and O. Ebong, "Artemisinin combination therapies safe or not safe?" The Internet Journal of Pharmacology, vol. 10, article 1, 2012. 


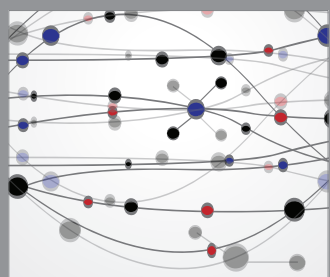

The Scientific World Journal
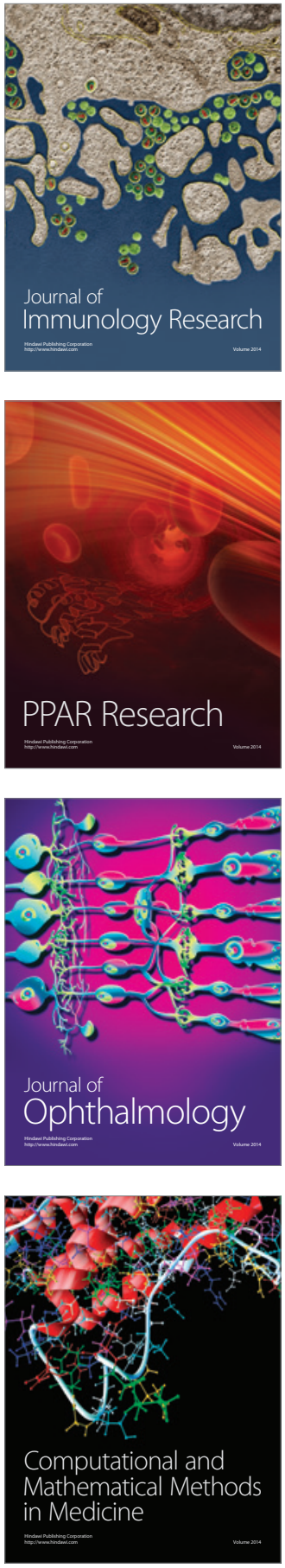

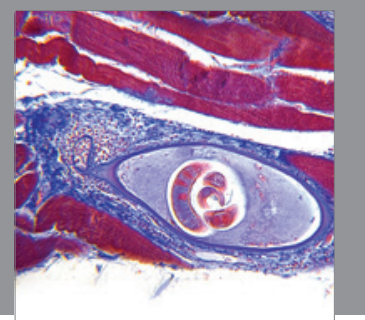

Gastroenterology

Research and Practice
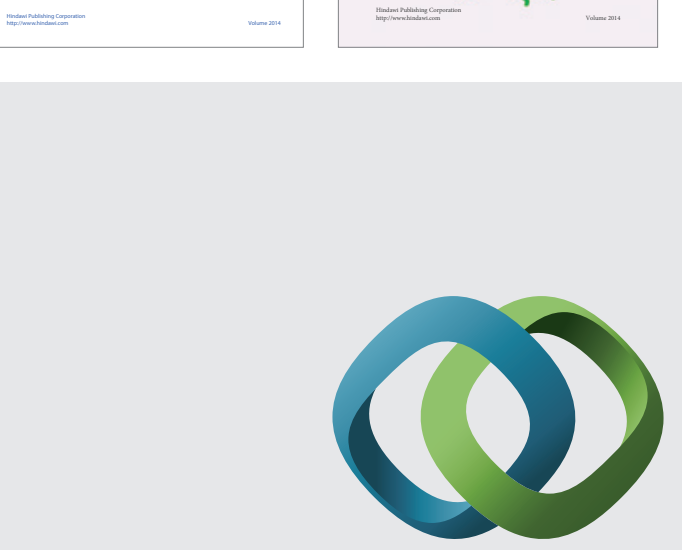

\section{Hindawi}

Submit your manuscripts at

http://www.hindawi.com
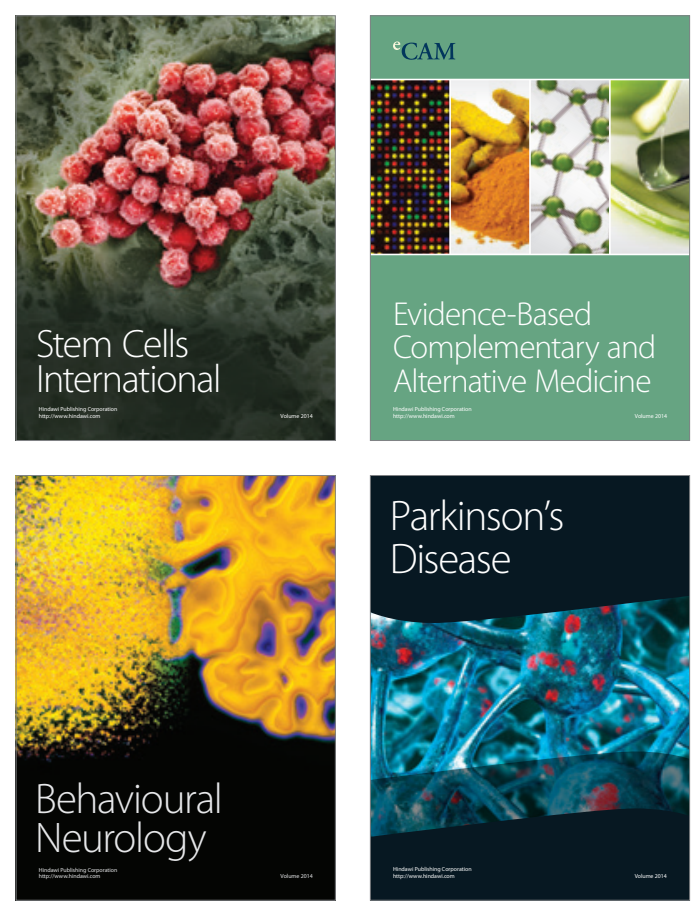

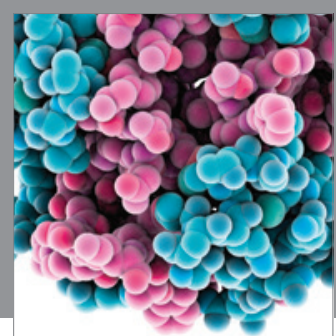

Journal of
Diabetes Research

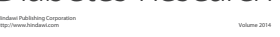

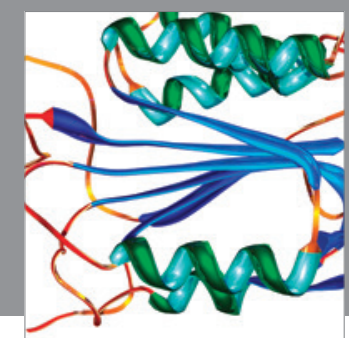

Disease Markers
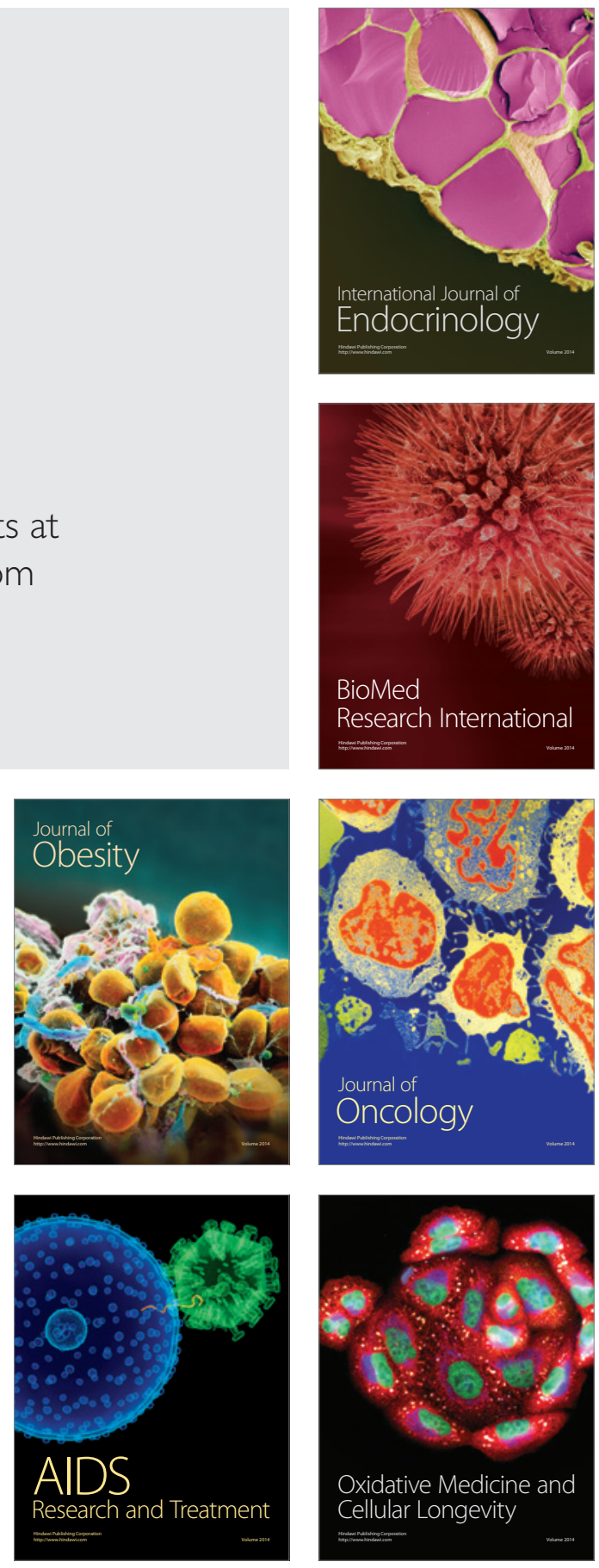